\title{
Agência dos agricultores na interface dos sistemas formal $e$ informal de conhecimento $e$ inovação
}

\author{
Iolanda Araujo Ferreira dos Santos \\ Universidade Federal de Santa Maria - Santa Maria - RS - Brasil \\ ORCID: 0000-0001-7595-7884 \\ Vivien Diesel \\ Universidade Federal de Santa Maria - Santa Maria - RS - Brasil \\ ORCID: 0000-0003-2939-9660
}

\begin{abstract}
Resumo
Neste artigo nos propomos a refletir sobre a dinâmica da inovação na agricultura em âmbito local, conferindo atenção à agência do agricultor na interface de sistemas de conhecimento e inovação diferenciados (formal e informal). Para tanto, tomamos como base a descrição de um caso de estruturação de um sistema de inovação local para introdução da piscicultura em Santa Maria, Rio Grande do Sul (RS). Os principais dados analisados na pesquisa foram coletados através de entrevistas com agricultores e agentes de assistência técnica locais. Observamos mudanças na configuração do sistema de inovação a medida que organizações de agricultores foram formadas e assumiram protagonismo na implementação de um projeto de profissionalização da piscicultura. Apesar do esforço em prol da padronização dos sistemas de criação com base em conhecimentos e inovações oriundos do sistema formal, identificamos uma elevada heterogeneidade nos componentes tecnológicos dos sistemas de criação de peixes. Tendemos a interpretar que estes resultados podem estar associados a agência dos agricultores, que no esforço de "encaixar" a piscicultura em suas estratégias sócio-produtivas e sistemas de produção, promovem a diferenciação constante dos formatos tecnológicos. Tal dinâmica tende a ser realizada mediante hibridização de conhecimentos técnico-científicos e locais.
\end{abstract}

Palavras-chave: Sistemas de inovação. Políticas Públicas. Agricultura familiar. Piscicultura.

\section{Farmers agency at the interface of formal and informal knowledge and innovation} systems

\section{Abstract}

In this article we propose to reflect about the dynamics of innovation in agriculture at the local level, paying attention to the interface of differentiated knowledge and innovation systems (formal and informal). For this, we based on the description of a case of structuring a local innovation system for the introduction of pisciculture in Santa Maria, Rio Grande do Sul (RS). The data analyzed in the survey were collected, essentially, through interviews with farmers and local technical assistance agents. Changes in the innovation system configuration were observed as farmers' organizations were formed and gained power in the 
fish farming professionalization project. Despite the effort to use technical knowledge for standardize the fish farming systems, a high heterogeneity was observed. We tend to suppose that this heterogeneity derives from farmers agency that "fit" pisciculture into their socio-productive strategies in different ways, adopting an adaptive logic that fosters the constant renewal of technological formats. Such dynamics tend to be realized by hybridization of technical-scientific and local knowledge.

Keywords: Innovation systems; Public Policies; Family Farming; Pisciculture.

\section{Agencia de agricultores en la interfaz de los sistemas formales e informales de conocimiento e innovación}

\section{Resumen}

En este artículo proponemos reflexionar sobre la dinámica de la innovación en la agricultura a nivel local, prestando atención a la agencia de agricultores en la interfaz de los sistemas diferenciados de conocimiento e innovación (formales e informales). Con este fin, tomamos como base la descripción de un caso de estructuración de un sistema de innovación local para la introducción de la piscicultura en Santa María, Rio Grande do Sul (RS). Los principales datos analizados en la investigación se recopilaron a través de entrevistas con agricultores y agentes locales de asistencia técnica. Observamos cambios en la configuración del sistema de innovación a medida que se formaban las organizaciones de agricultores y que estas ganaran el protagonismo en la implementación de un proyecto de profesionalización de la piscicultura. A pesar del esfuerzo por utilizar el conocimiento tecnico-cientifico para estandarizar las practicas produtivas, identificamos una alta heterogeneidad en los componentes tecnológicos en la cría de peces. Tendemos a interpretar que estos resultados pueden estar asociados con la agencia del agricultor, que en el esfuerzo por "encajar" la piscicultura en sus estrategias socio-productivas y sistemas de producción, promueven la diferenciación constante de los formatos tecnológico. Esta dinámica tiende a lograrse mediante la hibridación del conocimiento técnico-científico y local.

Palabras clave: Sistemas de innovación. Politicas publicas. Agricultura familiar. Piscicultura.

\section{Introdução}

A temática "inovação" se destaca pelo renovado interesse que tem despertado nas mais distintas sociedades ao longo do tempo. Conforme contextualizam Bonny e Giuliani (2012), o tema é onipresente no discurso contemporâneo seja por sua associação com um imaginário social que valoriza o novo, por sua presença em um discurso político ideológico que valoriza a competitividade, como também pela influência daqueles que consideram a inovação uma característica intrínseca do comportamento humano em resposta a um mundo dinâmico, sempre em transformação.

A construção de um imaginário de legitimação da inovação tem por base representações sociais construídas em tempos remotos. No século XIX, ao se aceitar a proposição acadêmica de que todas as sociedades tendem a evoluir, progredir ou se desenvolver, afirmou-se a desejabilidade da mudança continua, orientada ao aperfeiçoamento técnico e social. Seguindo nesta linha, gestores do desenvolvimento têm assumido a promoção do desenvolvimento pela via da mudança tecnológica como um dos seus principais desafios e, neste esforço, recentemente tem requerido que a academia gere subsídios teóricos que qualifiquem suas iniciativas. 
O desafio da promoção da mudança tecnológica na agricultura foi, por muito tempo, percebido como o desafio de possibilitar que as soluções tecnológicas geradas nas instituições de pesquisa científica chegassem a quem poderia aplicá-las. Neste contexto a Teoria da Difusão de Inovações (ROGERS 1966, 2003) constituiu-se na interpretação da dinâmica social de mudança tecnológica que teve maior influência na concepção de políticas e estratégias para o desenvolvimento agrícola, tanto em países do norte quanto do sul global. Entretanto, diversos autores tem argumentado que há necessidade de rever o imaginário desenvolvimentista hegemônico (ESCOBAR, 1995; CHAMBERS, 1995, 2017) e a aplicabilidade da Teoria da Difusão de Inovações (GLOVER et al, 2019). Neste contexto, identifica-se a emergência recente de uma grande diversidade de abordagens teóricas alternativas para interpretação da dinâmica da mudança tecnológica na agricultura.

Dentre os aspectos que vem despertando atenção dos pesquisadores incluem-se a "institucionalidade" e o papel do "usuário" nos processos de inovação. Com relação à questão da "institucionalidade", pesquisadores tem chamado atenção para a diversidade de atores implicados nos processos de inovação (seja com atuação na geração de tecnologias, condicionamento ou facilitação do processo) e, para contemplar essa complexidade de relações tem sido recorrente a utilização da noção de sistemas de inovação (HIRVONEN, 2009; TOURAND et al., 2015). Com relação a questão do papel do "usuário" na dinâmica de inovação (BENOUNICHE et al., 2014; GLOVER et al. 2019), critica-se a aplicabilidade da noção de adoção (vinculada a Teoria da Difusão de Inovações) a qual pressupõe um papel relativamente "passivo" do "usuário"; argumentando-se contemporaneamente em favor de noções que reconhecem a capacidade de agência deste.

No presente trabalho nos propomos a realizar uma releitura da dinâmica da mudança tecnológica no âmbito da agricultura familiar, analisando criticamente as contribuições e aplicabilidade das noções de sistemas de inovação e agência do agricultor. Para tanto, além de uma revisão bibliográfica sobre conceitos relacionados, realizamos um esforço para analisar a aplicabilidade destes conceitos para interpretar um caso específico, caracterizado pela introdução e desenvolvimento da piscicultura no âmbito da agricultura familiar no meio rural do sul do Brasil.

No estudo de caso, para avançar na compreensão da estruturação do sistema de inovação, realizamos um resgate do histórico do desenvolvimento da piscicultura no município. Além da revisão bibliográfica, para recompor este histórico realizamos o estudo de dados secundários, resgate de documentos sobre políticas públicas locais e 4 entrevistas a "informantes-chaves" (sendo 1 técnico da Secretaria Municipal de Desenvolvimento Rural (SMDR), 1 representante da Associação de Piscicultores de Santa Maria (APISM), 1 técnico do escritório local da EMATER/RS ${ }^{1}$ e 1 agricultor pioneiro na piscicultura no município). Num segundo momento, para compreender a agência do agricultor, entre novembro de 2014 e janeiro de 2015 realizamos entrevistas à 10 agricultores, bem como, visitamos suas unidades produtivas para observação das condições e técnicas de criação dos peixes. Nas entrevistas buscamos recuperar a trajetória tecnológica de diferentes componentes

1 A EMATER/RS- ASCAR é a instituição responsável pelo serviço oficial de assistência técnica e extensão rural no estado do Rio Grande do Sul (http://www.emater.tche.br/site/). No trabalho ao referirmos a instituição estadual utilizaremos o termo EMATER/RS e quando nos referirmos ao escritório local utilizaremos somente EMATER. 
específicos dos sistemas de criação de peixes, com o objetivo de identificar e caracterizar a variabilidade de formatos tecnológicos utilizados ao longo do tempo. Além de identificar e caracterizar a diversidade de formatos tecnológicos buscamos resgatar as motivações para as mudanças e a origem dos formatos alternativos utilizados (elucidando eventuais vínculos com sistemas formais de conhecimento e inovação).

\section{Aproximações teóricas às configurações e dinâmicas de sistemas de inovação na agricultura familiar}

Considerando-se a importância concedida à Ciência enquanto fonte de novos conhecimentos e técnicas superiores, por muito tempo as atenções dos gestores de políticas estiveram voltadas às institucionalidades públicas, que foram criadas para promover a desejada mudança tecnológica na agricultura. Assim, via de regra, os desafios relativos a promoção da mudança tecnológica foram tratados como questões associadas ao performance das organizações públicas de pesquisa, de extensão, relação entre elas e destas com políticas públicas. Entretanto, estudos empíricos conduzidos a partir de meados da década de 1980 passaram a evidenciar protagonismo de outros atores, até então não contemplados nos estudos sobre inovações. Uma das situações observadas, por exemplo, refere-se a importância das agroindústrias - tanto na geração de tecnologias quanto no condicionamento da mudança tecnológica entre agricultores (sobretudo nos casos em que se estabeleceram relações contratuais de integração). Do mesmo modo, pesquisadores apontaram a coexistência de diferentes motivações e articulações para a mudança tecnológica. Considerando a necessidade de contemplar a diversidade empírica e sistematiza-la, Engel (1997) propôs a distinção de cinco (5) tipos de configurações de sistemas de inovação (industry driven; policy driven; farmer driven; research \& development driven e donor driven), distintos quanto aos atores protagonistas, líderes, grupos rurais envolvidos, motivação principal para inovação, principal fonte de poder (influência), principais mecanismos de coordenação e formas de controle (Quadro 1).

\section{Quadro 1 - Ferramenta conceitual: Síntese das configurações básicas e suas principais características}

\begin{tabular}{|c|c|c|c|c|c|}
\hline $\begin{array}{l}\text { Tipo de } \\
\text { configuração/ } \\
\text { Características }\end{array}$ & Industry driven & Policy driven & Farmer driven & $\begin{array}{l}\text { Research \& } \\
\text { Development } \\
\text { driven }\end{array}$ & Donor driven \\
\hline $\begin{array}{l}\text { Atores } \\
\text { protagonistas }\end{array}$ & $\begin{array}{l}\text { Comércio } \\
\text { agrícola/ } \\
\text { indústrias, } \\
\text { agricultores } \\
\text { empresariais }\end{array}$ & $\begin{array}{l}\text { Política } \\
\text { agrícola/ } \\
\text { extensão/ } \\
\text { agricultores } \\
\text { modelo }\end{array}$ & $\begin{array}{l}\text { Política } \\
\text { agrícola/ } \\
\text { lideranças de } \\
\text { agricultores }\end{array}$ & $\begin{array}{l}\text { Pesquisa } \\
\text { agrícola/ } \\
\text { agricultores } \\
\text { inovadores }\end{array}$ & $\begin{array}{l}\text { Agricultores } \\
\text { beneficiários } \\
\text { projetos/ } \\
\text { agricultores } \\
\text { modelo }\end{array}$ \\
\hline Líderes & $\begin{array}{ll}\text { Atores } & \text { do } \\
\text { mercado } & \end{array}$ & $\begin{array}{lr}\text { Gestores } & \text { de } \\
\text { políticas } & \text { e } \\
\text { agricultores } & \end{array}$ & $\begin{array}{l}\text { Organizações } \\
\text { de agricultores }\end{array}$ & $\begin{array}{l}\text { Instituições de } \\
\text { pesquisa (inter) } \\
\text { nacional }\end{array}$ & Doadores \\
\hline $\begin{array}{l}\text { Grupos rurais } \\
\text { envolvidos }\end{array}$ & $\begin{array}{l}\text { Agricultores } \\
\text { comerciais }\end{array}$ & $\begin{array}{l}\text { Agricultores } \\
\text { vinculados } \\
\text { programa }\end{array}$ & $\begin{array}{l}\text { Agricultores } \\
\text { organizados }\end{array}$ & $\begin{array}{l}\text { Agricultores } \\
\text { tecnificados }\end{array}$ & $\begin{array}{l}\text { Agricultores } \\
\text { vinculados ao } \\
\text { programa }\end{array}$ \\
\hline
\end{tabular}




\begin{tabular}{|c|c|c|c|c|c|}
\hline $\begin{array}{l}\text { Tipo de } \\
\text { configuração/ } \\
\text { Características }\end{array}$ & Industry driven & Policy driven & Farmer driven & $\begin{array}{l}\text { Research \& } \\
\text { Development } \\
\text { driven }\end{array}$ & Donor driven \\
\hline $\begin{array}{l}\text { Motivação } \\
\text { principal para } \\
\text { inovação }\end{array}$ & $\begin{array}{l}\text { Eficiência/ } \\
\text { qualidade do } \\
\text { produto }\end{array}$ & $\begin{array}{l}\text { Objetivos } \\
\text { políticos }\end{array}$ & $\begin{array}{l}\text { Necessidades } \\
\text { dos } \\
\text { agricultores }\end{array}$ & $\begin{array}{l}\text { Avanços } \\
\text { técnicos }\end{array}$ & $\begin{array}{l}\text { Objetivos } \\
\text { intervenção }\end{array}$ \\
\hline $\begin{array}{l}\text { Principal fonte } \\
\text { de } \\
\text { poder/influência }\end{array}$ & $\begin{array}{lr}\text { Articulações } & \text { de } \\
\text { mercado em } & \text { em } \\
\text { termos } & \text { de } \\
\text { preços, } & \\
\text { controle } & \text { de } \\
\text { qualidade } & \text { e } \\
\text { recursos } & \end{array}$ & $\begin{array}{l}\text { Políticas/regras } \\
\text { e regulamentos, } \\
\text { recursos }\end{array}$ & $\begin{array}{l}\text { Influência } \\
\text { política/ } \\
\text { recursos }\end{array}$ & $\begin{array}{l}\text { (Superioridade) } \\
\text { Tecnologia, } \\
\text { expertise } \\
\text { técnica }\end{array}$ & $\begin{array}{l}\text { Recursos } \\
\text { financeiros, } \\
\text { expertise } \\
\text { técnica, }\end{array}$ \\
\hline $\begin{array}{l}\text { Principais } \\
\text { mecanismos de } \\
\text { coordenação }\end{array}$ & $\begin{array}{l}\text { Padronização } \\
\text { dos produtos/ } \\
\text { pacotes } \\
\text { técnicos }\end{array}$ & $\begin{array}{l}\text { Supervisão } \\
\text { direta, } \\
\text { padronização } \\
\text { dos processos } \\
\text { de trabalho/ } \\
\text { pacotes } \\
\text { técnicos }\end{array}$ & $\begin{array}{l}\text { Padronização } \\
\text { de interesses e } \\
\text { normas }\end{array}$ & $\begin{array}{l}\text { Padronização } \\
\text { de habilidades/ } \\
\text { formação }\end{array}$ & $\begin{array}{l}\text { Ajustes } \\
\text { mútuos, } \\
\text { padronização } \\
\text { de pacotes } \\
\text { técnicos, } \\
\text { habilidades e } \\
\text { processos de } \\
\text { trabalho }\end{array}$ \\
\hline $\begin{array}{l}\text { Forma de } \\
\text { controle }\end{array}$ & $\begin{array}{l}\text { Planilhas de } \\
\text { controle } \\
\text { individuais }\end{array}$ & $\begin{array}{l}\text { Políticas } \\
\text { governamentais }\end{array}$ & $\begin{array}{l}\text { Interesses dos } \\
\text { agricultores }\end{array}$ & $\begin{array}{l}\text { Comunidade de } \\
\text { pesquisa }\end{array}$ & $\begin{array}{l}\text { Políticas dos } \\
\text { doadores }\end{array}$ \\
\hline
\end{tabular}

Fonte: (ENGEL, 1997, p. 104) - Adaptação e tradução livre dos autores

A observação da diversidade empírica levou Engel (1997) a reconhecer ainda que, em algumas situações, formam-se configurações menos consolidadas e mais dinâmicas, as quais ele denominou "redes" (networks). Em trabalho mais recente, buscando identificar as configurações emergentes em processos de inovação no contexto europeu (em iniciativas orientadas à sustentabilidade), Dockès et al (2011) observaram tendência a um aumento da diversidade de tipos de atores que participam e exercem liderança nos processos de inovação, bem como a tendência à maior hibridização e fluidez nas relações estabelecidas entre os atores. ${ }^{2}$ Assim, apontam que tanto atores relacionados aos sistemas formais de conhecimento, quanto outros atores socioeconômicos, usuários finais e/ou gestores de políticas podem participar dos sistemas de inovação. Os autores (2011) compreendem que estes atores podem estar articulados em redes com diferentes orientações, por exemplo, em research driven innovation; farmers networking driven innovation; producer and consumer driven innovation, territorial partnership driven innovation ou coalition drive innovation. Faure et al. (2019), por sua vez, chamam atenção para a diferenciação das configurações dos sistemas de inovação conforme a fase do processo de inovação. Para os autores, podem ser distinguidas a fase de geração inicial de uma ideia, inspiração (em que um grupo informal se articula em torno da ideia), planejamento, desenvolvimento, realização, disseminação e incorporação. Como cada fase requer um tipo diferenciado de serviço de apoio, há uma tendência de mudança nos atores protagonistas em cada fase e, por consequência, na configuração do sistema ao longo do tempo. A partir de aportes teóricos desta natureza colocou-se a possibilidade de interpretar a mudança tecnológica nos

2 Estas observações estão em sintonia com as tendências apontadas pelos estudos sobre a institucionalidade dos sistemas agroalimentares alternativos (DEVERRE; LAMINE, 2010) e sobre pluralismo na extensão rural, que tem apontado para a diversidade de agentes envolvidos em questões relativas a orientação técnica na agricultura (GFRAS, 2012). 
marcos dos sistemas de inovação, considerados como uma resultante de um trabalho de articulação (networking), coordenação e convergência de atores com diferentes perspectivas iniciais quanto à inovação.

Outro ponto que requer revisão, conforme adiantado anteriormente, referese a questão da agência do "usuário" (agricultor). Sob os marcos da abordagem dos sistemas de inovação, deduz-se inicialmente que, como resultado dos esforços de coordenação, há tendência à convergência tecnológica entre os participantes de um dado sistema. Entretanto, esta hipótese choca-se com evidencias que vem sendo apresentadas acerca da capacidade de agência dos agricultores, a qual mostra-se relevante mesmo em processos caracterizados pela introdução de "pacotes tecnológicos" de origem externa. ${ }^{3}$ Benouniche et al. (2014), por exemplo, descrevem um processo de bricolage no contexto da introdução da irrigação por gotejamento no Marrocos. Naquele caso, os autores observam que, quando esta tecnologia estava sendo introduzido a partir de referências estrangeiras, "adaptações" feitas por agricultores foram essenciais para colocá-la e mantê-la em funcionamento sob as condições locais. Posteriormente, o aperfeiçoamento tecnológico realizado pelos fabricantes, a estruturação dos serviços de assistência técnica e os subsídios governamentais para utilização desta tecnologia possibilitaram o uso segundo a referência técnica formal, reduzindo-se as "adaptações" dos agricultores - no que veio a ser denominado um processo de "profissionalização" na atividade. Por fim, mesmo agricultores para os quais esta tecnologia não se mostrava perfeitamente adaptada às suas condições, tenderam a seguir determinados parâmetros técnicos formais com vistas a possibilidade de acesso a subsídios governamentais para uso dela (reduzindo-se a possibilidade de "adaptação"). Benouniche et al (2014) mencionam que o processo de adaptação foi nomeado como bricolage e que as gerações mais antigas atribuem valor negativo a este comportamento, considerando-o contrário à profissionalização da atividade. As gerações mais jovens, por sua vez, reconhecendo o caráter dinâmico das condições naturais e do contexto socioeconômico, atribuem à bricolage um valor positivo, considerando-a précondição para sustentabilidade de determinada atividade.

Glover et al (2019) adotam uma postura mais radical na avaliação da capacidade de agência dos agricultores. Partindo de uma crítica à representação dos agricultores como simples aplicadores de pacotes tecnológicos (vinculada à noção clássica de adoção), os autores (2019) argumentam que a tecnologia não pode ser considerada um pacote (uma caixa preta) frente à qual cabem somente duas opções (adotar ou não) pois as evidencias recentes apontam que, via de regra, os agricultores "desempacotam, recombinam e reconfiguram" a tecnologia com vistas a adaptação da mesma ao seu contexto. Para os autores a tecnologia deve ser tratada como uma proposta que combina de uma maneira singular um componente material, um componente técnico e um componente relacional (modo de engajamento na produção agrícola). Consideram, também, que a proposta oriunda de um sistema formal geralmente é apresentada em "encontros" que reúnem técnicos e potenciais "usuários" e ela pode ser percebida pelos "usuários" de diferentes formas. Ou seja, a proposta pode, ou não, ser percebida como uma "oportunidade" relevante. A

3 Para Smith e Bargdon (2015) a maior parte das inovações dos agricultores permanece não documentada ou é registrada em relatórios e documentos de circulação restrita, de modo que é invisível para cientistas e acadêmicos do setor formal. 
avaliação da "oportunidade", por sua vez, é subjetiva, situacional e relacional pois o "usuário" pode perceber "oportunidades" não visualizadas por aquele que concebeu a proposta, avaliando a oportunidade de uso da tecnologia tanto no formato apresentado, quanto num formato alternativo idealizado pelo usuário, derivado da recombinação criativa dos componentes da proposta (elementos materiais, técnicas e relacionais). Tal processo subjaz ao esforço de adaptação de propostas aos diferentes contextos e explica a tendência à emergência de soluções tecnológicas originais e trajetórias tecnológicas individuais particulares. Para os autores os resultados de uma reconfiguração tecnológica são mais imprevisíveis a medida que aumenta a complexidade da mudança tecnológica (ou seja, quanto maior o número e diversidade dos materiais componentes; rol de habilidades, técnicas e conhecimentos requeridos, abrangência da redes de relações; complexidade dos frameworks institucionais e reconfiguração sociotécnica) (GLOVER et al., 2019).

Seguindo a literatura sobre a geração de tecnologias para agricultores familiares, identifica-se emergência de propostas metodológicas orientadas a contemplar o necessário ajuste `as condições locais de sua aplicação. Enquanto alguns defendem que estas adaptações às condições locais sejam realizadas por pesquisadores, outros reconhecem que o desenvolvimento de soluções tecnológicas pode se favorecer da participação (e agencia) dos agricultores. Atentos a diversidade de modelos orientadores da pesquisa aplicada, Smith e Bargdon (2015) identificam três abordagens distintas quanto ao papel do agricultor: innovating for the farmers, innovating with farmers e innovating by farmers. Na abordagem de transferência de tecnologia (innovating for the farmers), o agricultor é tratado como adotante da tecnologia gerada pelo sistema formal e considera-se que, ao adotar, inova. Entendemos que este tipo de abordagem tende a ser dominante em configurações onde a liderança do sistema conduz a inovação com vistas ao aumento da qualidade e eficiência da produção mediante padronização de processos e produtos. ${ }^{4} \mathrm{Na}$ abordagem de inovação com os agricultores (innovating with farmers) há um reconhecimento e busca pela exploração da capacidade do agricultor para adaptação das tecnologias relativamente mais flexíveis, geradas pelo sistema formal. Este tipo de abordagem tenderia a ser dominante em configurações lideradas por organizações de produtores, por exemplo, ou com orientação farmer led. Por fim, numa terceira abordagem confere-se ênfase à capacidade de inovação dos agricultores, preconizando-se um protagonismo destes (innovating by farmers) com os atores externos reduzidos à uma posição de apoio. Este tipo de abordagem tenderia a ocorrer em processos de inovação "espontâneos", ou com orientação a "adaptabilidade" às diferentes condições. Para a presente pesquisa importam, sobretudo, os dois primeiros modelos pois mais próximos à diversidade dos processos empíricos observados.

A partir dos aportes revisados, compreendemos que a interpretação da dinâmica da mudança tecnológica (e da inovação) requer que se considere, a configuração social na qual este processo ocorre (tipo de sistema de inovação) o modelo de pesquisa no desenvolvimento tecnológico e, sobretudo, a potencial agência do agricultor. Enquanto algumas propostas tecnológicas consideram a

4 Conforme apontam Smith e Bargdon (2015, p.10) embora os discursos tenham se alterado em defesa de estratégias de innovating with farmers, o modelo innovating for farmers ainda é a estratégia dominante. 
agência do agricultor necessária para definições adicionais de acoplamento de uma dada tecnologia às condições locais, outras consideram a eventual agência do agricultor como prejudicial ao desempenho de um "pacote tecnológico" pré-definido pela pesquisa. Entretanto, para Glover et al. (2019) a agência do agricultor é inerente aos processos de utilização da tecnologia e, por isso, grande atenção deve ser dada as adaptações realizadas, que definem trajetórias tecnológicas particulares.

\section{Aproximações às configurações e dinâmica local de inovação: o caso da piscicultura em Santa Maria, RS}

Santa Maria constitui um município situado na região central do Rio Grande do Sul (RS), com características urbanas muito destacadas. Segundo dados do Censo Demográfico do IBGE, em 2010 o município possuía uma população estimada de 261.031 habitantes, dos quais 248.347 residiam no meio urbano e somente 12.684 residiam no meio rural.

Ao se localizar em uma área de transição entre Depressão Central e Planalto, tem parte pequena de seu território na área de Rebordo da Serra Geral. O histórico de ocupação deste território está relacionado a estratégias governamentais de defesa (com presença de bases militares do exército e aeronáutica), estruturação de serviços de transporte de cargas e passageiros (ferrovias), de formação de comércio regional e prestação de serviços diversos, com destaque aos serviços educacionais (com presença de diversas universidades, dentre as quais a Universidade Federal de Santa Maria (UFSM), a qual possui um Centro de Ciências Rurais com orientação ao ensino, pesquisa e extensão). Fruto da diversidade das dinâmicas de ocupação, o município apresenta uma estrutura agrária heterogênea, com estabelecimentos rurais de tamanhos variados ${ }^{5}$, evidenciando-se a predominância numérica da agricultura familiar. ${ }^{6}$ A produção agropecuária - que constitui uma das múltiplas fontes de renda dos estabelecimentos (CANCELIER et al, 2017) - é, historicamente, diversificada, mas recentemente houve acentuada expansão do cultivo de soja que se tornou, segundo dados do sistema SIDRA/IBGE, a lavoura mais cultivada em 2017 (42.347 hectares), seguido pelo arroz (com 7.441 hectares). Dentre as demais lavouras, apenas a batata-inglesa alcança área significativa (1.619 hectares). No âmbito da produção animal destaca-se a criação de bovinos, seguida de ovinos e equinos. A piscicultura foi fomentada no município a partir de meados da década de 1990. Dados do Censo Agropecuário referentes a 2017 apontam que, neste ano, em 155 estabelecimentos havia criação de carpa e que em 37 estabelecimentos a criação de peixes foi comercializada. ${ }^{7}$ Embora o número total de agricultores que comercializaram peixe em 2017 não possa ser considerado alto, cabe reconhecer que esta é uma cadeia produtiva formada recentemente.

\footnotetext{
5 Dados preliminares do Censo Agropecuário de 2017 (acessados via sistema SIDRA/IBGE), evidenciam que o município tem 1.701 estabelecimentos agropecuários. A concentração fundiária se revela significativa ao considerar-se que estabelecimentos com mais de 100 hectares equivalem a cerca de $15 \%$ do total do numero de estabelecimentos e detém cerca de $78 \%$ da área total. Neste conjunto, os estabelecimentos com mais de 1.000 hectares detém cerca de $23 \%$ da área total.

6 De acordo com os dados do Censo Agropecuário de 2006 (IBGE), Santa Maria contava com 2.306 estabelecimentos agropecuários, dos quais somente 538 eram classificados como não familiares.

7 Dados do Censo Agropecuário de 2006 indicam 114 estabelecimentos agropecuários com produção de peixes em Santa Maria, sendo 78 destes caracterizados como familiares e 36 não-familiares.
} 
Uma aproximação à evolução da piscicultura em Santa Maria requer que se diferenciem quatro fases, distintas quanto as configurações do sistema de inovação e projeto perseguido.

A primeira fase, de inserção da piscicultura nos estabelecimentos rurais de Santa Maria, ocorreu no início da década de 90, quando a EMATER iniciou uma série de mobilizações, incluindo visitas individuais e realização de reuniões com agricultores. Após a mobilização inicial, a EMATER organizou - em parceria com a UFSM - alguns cursos sobre piscicultura. Os "pioneiros" na criação de peixes, entrevistados nessa pesquisa, relataram que começaram a "enxergar" a piscicultura como uma alternativa de atividade produtiva somente após a participação nestes cursos. Convém contextualizar essa iniciativa municipal, reconhecendo que a mobilização de agricultores em torno à piscicultura seguia uma orientação da EMATER/RS, que, desde meados da década de 1980 promovia a diversificação das atividades produtivas nas "pequenas propriedades". ${ }^{8}$ Entendemos que a piscicultura era percebida como uma alternativa para diversificação pela possibilidade de utilização de espécies de peixes filtradoras ou onívoras, que possibilitavam o aproveitamento de subprodutos da unidade produtiva, e pelo valor proteico do alimento (peixe), que permitia o enriquecimento da dieta das famílias. Assim, não foi previsto, nesse primeiro momento, apoio à estratégias de comercialização da produção.

Os entrevistados indicam que logo depois das primeiras ações de favorecimento da piscicultura, houve uma modificação substantiva no "projeto" perseguido pelos atores envolvidos na promoção da atividade. De acordo com o informante 4, um agricultor mais capitalizado, em viagem para outro município, observou a comercialização do peixe vivo em caixas de água e resolveu replicar essa idéia em Santa Maria, utilizando uma piscina de plástico para comercializar, em uma feira local, o peixe produzido por ele. A partir daí, ainda em 1993, os agricultores que já possuíam peixes em tamanho e quantidade suficiente para comercializar, aproveitaram a época da Semana Santa para colocar o peixe vivo à venda na mesma feira. Então, a exemplo do que já acontecia em outros municípios do Rio Grande do Sul, a EMATER em parceria com a prefeitura municipal, viabilizou a comercialização dos peixes vivos em um espaço público no centro da cidade, configurando o início da Feira do Peixe Vivo de Santa Maria - que se tornou tradicional na época da Semana Santa. A partir de então, observou-se a maior articulação de um conjunto diverso de atores com vistas a viabilização desta atividade enquanto negócio, e esta "nova" orientação levou a necessidade de rever a proposta tecnológica inicial para piscicultura. Com a oportunidade de comercialização, entrevistados relatam que alguns agricultores passaram a visualizar essa atividade como potencial geradora de renda e, em resposta, realizaram investimentos buscando aumentar o número de viveiros e melhorar a qualidade de pescado produzido. Segundo o informante 4, os agricultores mais capitalizados, preocupados em criar condições para "profissionalização" da piscicultura no município, tentaram incentivar os demais a seguir a mesma lógica de investimento, promovendo reuniões entre piscicultores que, até então, só se encontravam nos cursos e palestras que a EMATER promovia.

\footnotetext{
8 Esta orientação, por sua vez, é uma resposta ao cenário de crise econômica da década de 1980 e aproxima-se ao ideário do movimento de tecnologias apropriadas que alcançou significativa repercussão política entre o final da década de 1970 e meados da década de 1990 (FRESSOLI; AROND, 2015).
} 
Essa iniciativa dos agricultores recebeu apoio da EMATER e da SMDR, e explica a emergência de iniciativas de fomento à atividade, pelas quais o município subsidiava a construção de reservatórios de água para piscicultura e distribuição de alevinos, assegurando também acesso à assistência técnica para a atividade. Em 1995 os agricultores criaram uma organização formal relacionada a piscicultura: a Associação de Piscicultores da Região Centro (APISCENTRO). Calgaro Neto (2008) comenta que a APISCENTRO surgiu basicamente para organizar os piscicultores do município com o objetivo de viabilizar a comercialização. Dessa forma, essa associação passou a ser responsável por promover a Feira do Peixe Vivo. Com a justificativa de que era necessário garantir a qualidade do pescado comercializado, a APISCENTRO começou a estabelecer condições para a participação de agricultores na feira. Compreendia-se que, idealmente, só os agricultores que fizessem parte da Associação e tivessem participado dos cursos estariam habilitados a comercializar na Feira do Peixe Vivo.

Em 2006 os atores que respondiam pela promoção da piscicultura no município buscaram "dar um passo além" na estruturação da cadeia produtiva. A partir da APISCENTRO, foi formalizada a criação da Cooperativa de Piscicultores da Região Centro (COOPISCENTRO). Os objetivos da COOPISCENTRO relacionavam-se a estruturação da cadeia produtiva, criando-se expectativas em torno à agroindustrialização do pescado, o que permitiria o aumento e manutenção da demanda por pescado ao longo do ano, e não somente no período da Feira do Peixe Vivo (CALGARO NETO e DIESEL, 2009). A atividade de formação técnica relacionada a piscicultura promovida no município passou, então, a ser organizada pela COOPISCENTRO, contando, via de regra, com o apoio financeiro e técnico da EMATER e da UFSM. Nesta fase buscava-se consolidar a piscicultura enquanto atividade especializada e conduzida profissionalmente. Para subsidiar a qualificação técnica dos agricultores na condução da atividade, foram realizados experimentos, análises de água nas unidades de produção e ministrados cursos e palestras para os cooperados.

A partir do final de 2013 observou-se um movimento de relativa desarticulação da organização dos atores em torno à COOPISCENTRO. A cooperativa foi extinta e criou-se uma nova associação: a Associação dos Piscicultores de Santa Maria (APISM). A APISM foi criada a partir do reconhecimento da necessidade de manter os produtores de peixe organizados e sob a justificativa de que uma Associação não demanda tanta burocracia para se manter quanto uma cooperativa. Mesmo que os entrevistados mencionassem planos de envolvimento da Associação na oferta de oportunidades de aperfeiçoamento técnico da piscicultura mediante realização de dias de campo e palestras, até 2015 (época de realização das entrevistas) a APISM concentrava suas atividades na promoção e organização da Feira do Peixe Vivo. $O$ projeto de "agroindustrialização" do pescado, por sua vez, passou a ser percebido como mais viável enquanto empreendimento de investidor individual do que como iniciativa coletiva de organização de agricultores.

\subsection{A inserção da piscicultura nos sistemas de produção dos agricultores familiares}

O resgate da evolução da piscicultura no município de Santa Maria permitiu identificar que o sistema de inovação se reconfigurou ao longo do tempo, 
associando-se a distintos projetos. ${ }^{9}$ Neste sentido, no período analisado (1990 a 2015) diferencia-se, sobretudo, uma motivação inicial de promover a piscicultura enquanto atividade complementar às demais atividades do sistema de produção e orientada à subsistência das famílias; de uma motivação posterior - de promoção da piscicultura como alternativa de geração de renda (seja pelo atendimento à demanda sazonal do mercado local (Feira do Peixe na Semana Santa) e/ou abastecimento da demanda de matéria-prima de uma agroindústria de beneficiamento de peixe a ser conformada). ${ }^{10}$

Os relatos de entrevistados permitem observar, também, que a mudança de projeto, via de regra, implicou numa releitura quanto aos desafios tecnológicos implicados. Neste sentido, sob o projeto inicial da piscicultura como atividade complementar, integrada ao sistema de produção, houve maior preocupação com a seleção e adaptação dos componentes do sistema de criação às condições locais com vistas ao máximo aproveitamento dos recursos disponíveis e respeito às preferências e projetos das famílias, sobretudo em um contexto caracterizado por heterogeneidade nas condições agroecológicas e sócio-produtivas. Por outro lado, quando a piscicultura passou a ser tratada como um negócio evidenciou-se maior preocupação da assistência técnica com a padronização do produto a ser comercializado e, consequentemente, com a definição de "pacotes tecnológicos" (sistema de criação de referência a ser adotado pelos agricultores para maximização da eficiência técnico-produtiva e da lucratividade) que permitissem a superação das deficiências constatadas nos sistemas de criação em uso (BALDISSEROTTO, 2009). Tal orientação foi tratada, pelos entrevistados, como parte do ideal de "profissionalização" na atividade.

Assim, a medida que os atores do sistema de inovação redefiniram projetos para a piscicultura no município, tiveram que repensar a natureza das ações de apoio à atividade. Dentre as ações de apoio além do fomento destacou-se, segundo relatos dos entrevistados, o esforço continuado da agência pública de orientação técnica (EMATER) (atuando em parceria com organizações de piscicultores e Universidade) de disponibilização de conhecimentos técnico-científicos para a introdução e aperfeiçoamento da atividade.

A realização de entrevistas aos agricultores que desenvolviam a piscicultura em 2015 revela que estes introduziram esta atividade em diferentes momentos, com motivações, graus diversos de investimento e de envolvimento com iniciativas coletivas (Quadro 2).

Quadro 2 - Perfil dos agricultores entrevistados

\begin{tabular}{|l|l|l|l|l|l|}
\hline $\begin{array}{l}\text { Identificação/ } \\
\text { anos na } \\
\text { piscicultura }\end{array}$ & $\begin{array}{l}\text { Tamanho } \\
\text { unidade } \\
\text { produtiva }\end{array}$ & $\begin{array}{l}\text { Principais } \\
\text { atividades } \\
\text { econômicas }\end{array}$ & $\begin{array}{l}\text { Tamanho } \\
\text { lâmina } \\
\text { agua }\end{array}$ & $\begin{array}{l}\text { Participação } \\
\text { organizações }\end{array}$ & Participação cursos \\
\hline $\begin{array}{l}\text { Agricultor } 1 \\
(24 \text { anos })\end{array}$ & 4,5 há & $\begin{array}{l}\text { Agricultura } \\
\text { (horticultura) }\end{array}$ & 2 ha & $\begin{array}{l}\text { COOPISCENTRO - } \\
\text { APISM }\end{array}$ & $\begin{array}{l}\text { Declara ter participado } \\
\text { ativamente dos cursos }\end{array}$ \\
\hline
\end{tabular}

\footnotetext{
9 Cabe observar que a evolução da piscicultura em Santa Maria, RS, segue, em termos gerais a tendência observada em outros municípios gaúchos, caracterizada por Cotrim (2002).

10 Seguindo Long (2007), observa-se que diferentes propostas tecnológicas se encontram, frequentemente, associadas a diferentes visões sobre desenvolvimento. Aplicando-se tal princípio ao caso da piscicultura percebese que se reproduz na piscicultura uma disputa de modelo comum na agricultura: entre um modelo de agricultura adaptativa/agroecológica e o modelo de agricultura considerado "moderno", onde se aplicam princípios de especialização produtiva, padronização do produto, eficientização técnica, controle e artificialização do ambiente.
} 


\begin{tabular}{|c|c|c|c|c|c|}
\hline & & & & & $\begin{array}{l}\text { promovidos pela EMATER e } \\
\text { pela organização dos } \\
\text { piscicultores, além de ter tido } \\
\text { uma relação mais próxima } \\
\text { com a UFSM por ter um filho } \\
\text { que cursou o técnico agrícola } \\
\text { nessa instituição de ensino. }\end{array}$ \\
\hline $\begin{array}{l}\text { Agricultor } 2 \\
(15 \text { anos) }\end{array}$ & 10 há & $\begin{array}{l}\text { Agricultura } \\
\text { (horticultura) }\end{array}$ & 2 ha & COOPISCENTRO & $\begin{array}{l}\text { Durante o período que fez } \\
\text { parte da cooperativa, } \\
\text { participou de cursos de } \\
\text { piscicultura. }\end{array}$ \\
\hline $\begin{array}{l}\text { Agricultor } 3 \\
\text { (11 anos) }\end{array}$ & 7 há & $\begin{array}{l}\text { Agricultura } \\
\text { (avicultura) }\end{array}$ & 1,5 ha & APISM & $\begin{array}{l}\text { Declara que participou de } \\
\text { poucos cursos referentes a } \\
\text { piscicultura. }\end{array}$ \\
\hline $\begin{array}{l}\text { Agricultor } 4 \\
\text { (4 anos) }\end{array}$ & 3,5 há & $\begin{array}{l}\text { Professor Ed. } \\
\text { Física }+ \\
\text { Agricultura } \\
\text { (Piscicultura) }\end{array}$ & $1 \mathrm{ha}$ & APISM & $\begin{array}{l}\text { Declara ter participado de } \\
\text { poucos cursos de } \\
\text { piscicultura. Destaca que tem } \\
\text { facilidade de pesquisar sobre } \\
\text { a piscicultura na internet e } \\
\text { que dialoga sempre com os } \\
\text { produtores mais } \\
\text { especializados sobre a } \\
\text { criação de peixes. }\end{array}$ \\
\hline $\begin{array}{l}\text { Agricultor } 5 \\
(22 \text { anos) }\end{array}$ & 50 há & $\begin{array}{l}\text { Representan } \\
\text { te Vendas + } \\
\text { Agricultura } \\
\text { (Piscicultura) }\end{array}$ & $10 \mathrm{ha}$ & $\begin{array}{l}\text { APISCENTRO - } \\
\text { COOPISCENTRO - } \\
\text { APISM }\end{array}$ & $\begin{array}{l}\text { Declara ter participado de } \\
\text { alguns cursos de piscicultura } \\
\text { apenas quando estava } \\
\text { iniciando na atividade. }\end{array}$ \\
\hline $\begin{array}{l}\text { Agricultor } 6 \\
(2 \text { anos) }\end{array}$ & 3 há & $\begin{array}{l}\text { Topografo + } \\
\text { Agricultura } \\
\text { (Piscicultura) }\end{array}$ & 0,6 ha & NAO & $\begin{array}{l}\text { Com formação superior em } \\
\text { Agronomia, declara que } \\
\text { nunca participou de cursos, } \\
\text { se reconhecendo como um } \\
\text { "autodidata". }\end{array}$ \\
\hline $\begin{array}{l}\text { Agricultor } 7 \\
(2 \text { anos) }\end{array}$ & 10 há & $\begin{array}{l}\text { Militar } \\
\text { aposentado + } \\
\text { Agricultura } \\
\text { (Piscicultura) }\end{array}$ & 1,2 ha & APISM & $\begin{array}{l}\text { Declara-se como assíduo } \\
\text { participante dos cursos de } \\
\text { piscicultura promovidos no } \\
\text { município. }\end{array}$ \\
\hline $\begin{array}{l}\text { Agricultor } 8 \\
(10 \text { anos })\end{array}$ & 35 há & $\begin{array}{l}\text { Agricultura + } \\
\text { Aposentador } \\
\text { ia }\end{array}$ & $1,2 \mathrm{ha}$ & NAO & $\begin{array}{l}\text { Declara que participou de } \\
\text { alguns cursos promovidos } \\
\text { pela EMATER }\end{array}$ \\
\hline $\begin{array}{l}\text { Agricultor } 9 \\
(25 \text { anos })\end{array}$ & 24 há & $\begin{array}{l}\text { Agricultura } \\
\text { (soja) }\end{array}$ & $3 \mathrm{ha}$ & $\begin{array}{l}\text { APISCENTRO - } \\
\text { COOPISCENTRO - } \\
\text { APISM }\end{array}$ & $\begin{array}{l}\text { Declara-se frequentador } \\
\text { assíduo dos cursos }\end{array}$ \\
\hline $\begin{array}{l}\text { Agricultor } 10 \\
\text { (24 anos) }\end{array}$ & 6 há & $\begin{array}{l}\text { Agricultura } \\
\text { (Horticultura } \\
\text { ) }\end{array}$ & 1,2 ha & $\begin{array}{l}\text { APISCENTRO - } \\
\text { COOPISCENTRO - } \\
\text { APISM }\end{array}$ & $\begin{array}{l}\text { Declara-se como participante } \\
\text { ativo nas reuniões e cursos } \\
\text { sobre piscicultura }\end{array}$ \\
\hline
\end{tabular}

$\mathrm{Na}$ caracterização do perfil dos entrevistados diferenciam-se dois grandes grupos, segundo a maior ou menor dependência da produção agropecuária na geração de renda familiar. Neste sentido, observa-se que muitas unidades produtivas são gestionadas por indivíduo com trajetória de atuação profissional vinculada a outras áreas que não a agricultura (4 de 10 entrevistados). Com relação a importância relativa da piscicultura na geração de renda para as famílias, o presente estudo corrobora com caracterizações apresentadas em pesquisas anteriores para 0 município (CARDOSO et. al, 2009; CALGARO NETO e DIESEL, 2009) e para o Rio Grande do Sul (COTRIM, 2002; BALDISSEROTTO, 2009). Em nenhum dos casos estudados a piscicultura se constituía como a principal fonte de renda para a família. Mesmo que se declarem "satisfeitos" com a atividade, a maioria dos entrevistados 
encara a piscicultura como uma atividade que "veio para somar nas receitas familiares". Sem alocar muitos recursos e esforços para a atividade, a maioria dos entrevistados considera que na piscicultura "o que vier é lucro", operando "como uma poupança", na qual eles investem "quando dá".

Entretanto, grande parte dos entrevistados reconhece que a introdução da piscicultura - no âmbito das atividades produtivas conduzidas no estabelecimento implicou em sua aproximação à conhecimentos técnico-científicos específicos para exercício da atividade.

\subsection{Descrição de trajetórias tecnológicas em componentes dos sistemas de criação}

Com vistas a uma aproximação à agência do agricultor na interface do sistema formal e informal de conhecimento e inovação, buscamos levantar a trajetória tecnológica dos agricultores entrevistados na piscicultura. As trajetórias tecnológicas dos agricultores na piscicultura podem ser observadas com diferentes graus de aproximação: pela diferenciação geral de sistemas de criação utilizados ou pela observação da trajetória tecnológica de componentes específicos dos sistemas de criação. Em nosso estudo optamos por realizar uma análise da trajetória por componente especifico, por entender que tal procedimento pode revelar, com maior detalhe, a agencia de cada agricultor ao abrir, recombinar e reconfigurar a proposta tecnológica desenhada pelo sistema formal - com a qual teve contato através de cursos, assistência técnica e por outros meios.

Para identificação dos componentes tecnológicos relevantes tomamos por base os itens destacados nos manuais de recomendação técnica para piscicultura na agricultura familiar. Neste sentido, foram utilizados manuais da EMBRAPA (LIMA et al 2013 a,b,c,d,e) e, complementarmente, em casos de componentes que demandavam consideração de especificidades regionais, os preceitos constantes no manual prático de piscicultura elaborado pela EMATER/RS (COTRIM, 1995). A análise dos dados foi realizada por componente, buscando a descrição das trajetórias de cada agricultor quanto ao formato tecnológico para cada um dos componentes selecionados. Os componentes tecnológicos selecionados, que foram investigados são os seguintes: formato e profundidade dos açudes; tipo de taipa; entrada e saída de água; fases de cultivo; manejo da água; espécies cultivadas; alimentação; tratamento de doenças; comercialização; integração com outras atividades. Além de identificar o conjunto de formatos que o agricultor declara ter utilizado desde que iniciou na piscicultura, levantamos as razões para a mudança tecnológica e origem do formato alternativo.

De modo geral, ao observarmos a trajetória tecnológica para cada componente do sistema de criação da piscicultura, observamos uma tendência geral de realização de mudanças no formato tecnológico com relativa frequência (indicando um processo de experimentação dos agricultores) mas com poucas situações de convergência quanto ao formato tecnológico experimentado. Tendo em vista as restrições de espaço para apresentação da totalidade dos dados levantados e com vistas a facilitar a discussão em torno aos objetivos da pesquisa, partimos da exposição e discussão dos condicionantes de mudanças tecnológicas divergentes e mudanças tecnológicas convergentes quanto aos formatos tecnológicos de componentes específicos. 
Para ilustrar as trajetórias tecnológicas identificadas em cada componente estudado, recorremos a construção de diagramas que demonstram como cada agricultor foi alterando (ou não) determinado formato tecnológico. Nos diagramas, apresentados nas seções seguintes, cada agricultor está representado por uma seta, diferenciando-se pela cor da seta, da seguinte forma: Agricultor 1: vermelho; Agricultor 2: verde escuro; Agricultor 3: azul escuro; Agricultor 4: laranja; Agricultor 5: verde claro; Agricultor 6: marrom; Agricultor 7: rosa; Agricultor 8: amarelo; Agricultor 9: azul claro; Agricultor 10: preto.

\subsubsection{Mudanças tecnológicas divergentes}

A tendência à trajetória tecnológica divergente pode ser ilustrada com observação do componente estrutura das "taipas" e do componente alimentação.

Com relação ao formato original do talude dos reservatórios de água utilizados para piscicultura - comumente chamados de "taipa" - cabe contextualizar que os reservatórios de agua utilizados para piscicultura são, geralmente, escavados na terra e, por isso, a "taipa típica” é de terra e sem nenhum tipo de proteção. Uma vez tendo experimentado a utilização da taipa de terra sem proteção, oito dos dez agricultores entrevistados realizaram mudanças na estrutura da taipa e, em alguns casos, identifica-se que as mudanças iniciais não foram consideradas suficientes ou apropriadas, e por isso foram realizadas, posteriormente, outras adaptações. Identificamos, no momento da pesquisa, nove tipos distintos de estrutura de taipas em uso entre 10 entrevistados, indicando elevada heterogeneidade de formatos tecnológicos em uso neste componente. A Figura 01 demonstra a trajetória tecnológica de cada agricultor no componente estrutura da taipa.

\section{Figura 1 - Trajetória tecnológica de cada agricultor relacionado à estrutura da taipa}

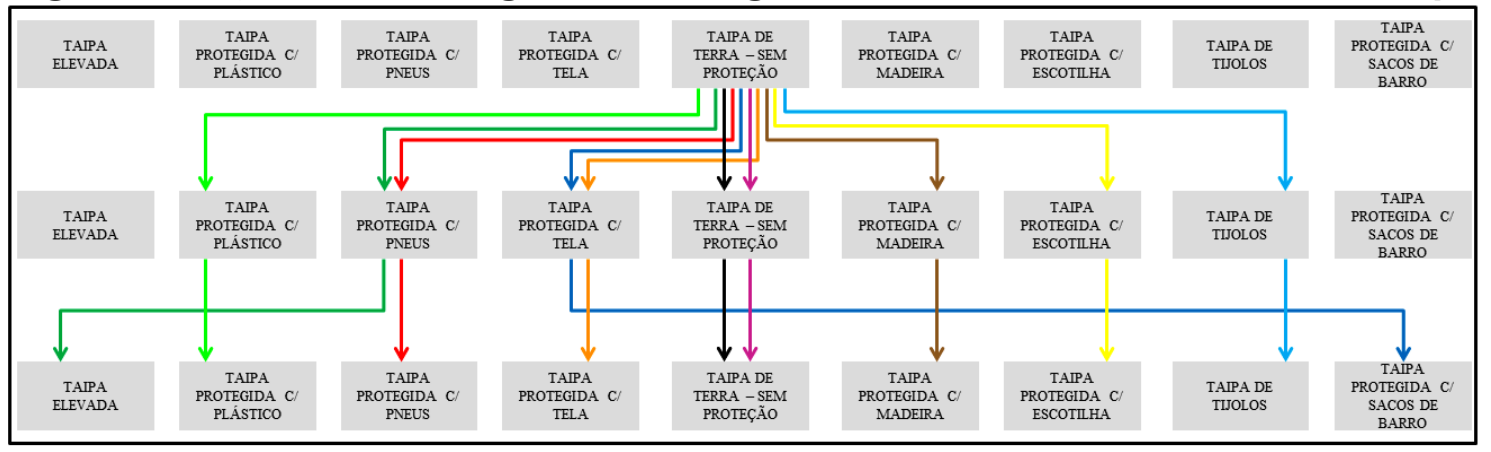

Nas entrevistas, os agricultores referiram à necessidade de introduzir mudanças na estrutura da taipa devido as ameaças causadas pelo comportamento da carpa húngara (principal espécie criada), que tem hábitos de revolver a terra a procura de alimento. Devido a sua viabilidade econômica, a maioria dos agricultores optou por manter a criação dessa espécie e realizar mudanças na estrutura da taipa com vistas a sua proteção. ${ }^{11}$ Quando questionados se receberam alguma orientação técnica (formação ou assistência técnica) sobre como proceder, todos colocaram que

11 Dois agricultores entrevistados consideraram que nenhuma alteração seria eficaz quanto aos danos que a carpa húngara causa na taipa e, por isso, optaram pela diminuição gradativa da criação desta espécie. 
em nenhum momento receberam recomendação técnica sobre como proteger as taipas, e que tampouco os cursos tratavam desse aspecto. Observa-se que na ausência de recomendações técnicas específicas no âmbito do sistema formal, houve protagonismo dos agricultores que, mediante experimentação, observação ou diálogo técnico com pares, foram ativos na busca de formatos tecnológicos alternativos para resolução do problema enfrentado. A estratégia mais comum foi a colocação de materiais diversos para proteção da taipa (plástico, pneus, tela, escotilha de trem, sacos de barro) observando-se que, em um caso se optou pelo uso de tijolos. Outro formato tecnológico identificado foi o de elevação da taipa (aumento da altura), implementado pelo agricultor que alegou recorrer à essa estratégia por já ter sofrido com a fuga de peixes pela superfície em épocas de chuva.

Outro aspecto em que a diversidade de formatos tecnológicos experimentados é muito evidente relaciona-se à alimentação dos peixes. O que se observou em campo foi a experimentação de uma grande diversidade de estratégias para alimentação dos peixes, distinguindo-se - para fins de análise- 16 formatos tecnológicos distintos. Identificaram-se, no momento da entrevista, 6 formatos tecnológicos distintos em uso que, por sua vez, representam combinação de materiais e práticas singulares, razão pela qual poderiam ser identificados subtipos (Figura 02). ${ }^{12}$

12 Entendemos que se fosse utilizada uma distinção mais acurada seria possível identificar uma variedade ainda maior de alternativas experimentadas, tendo em vista que "pastagem" ou "produtos da unidade produtiva" englobam uma grande diversidade de tipos e combinações de alimentos - variáveis estacionalmente em sua oferta. 
Figura 2 - Trajetória tecnológica de cada agricultor relacionada à alimentação

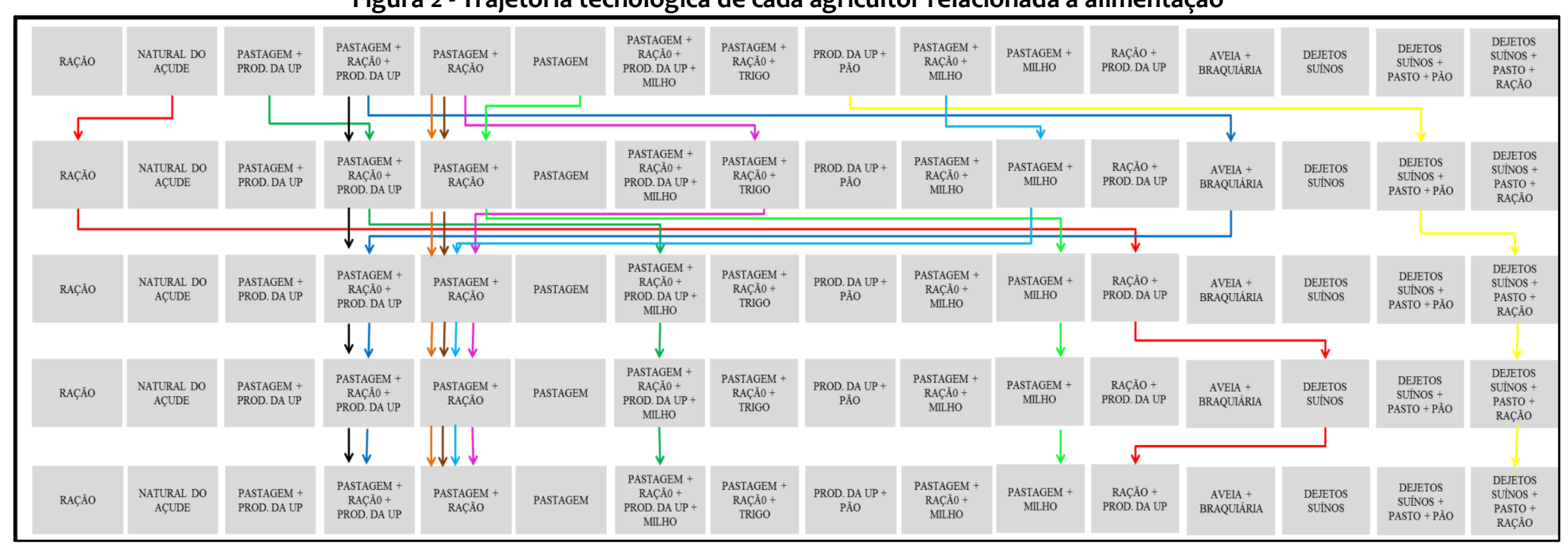


As informações disponíveis sobre a alimentação dos peixes indicam que os piscicultores mais antigos se orientavam, inicialmente, à maximização do aproveitamento de subprodutos da unidade produtiva. Este comportamento pode ter relação com a natureza da proposta tecnológica introduzida pelos agentes de desenvolvimento. ${ }^{13}$ Os entrevistados mencionam que apesar de ter acesso à informação técnica de que o fornecimento de alimento artificial (ração) otimizaria o tempo de cultivo e a qualidade da carne do pescado e, mesmo sendo incentivados a adotar a ração como fonte de alimento principal na piscicultura, julgaram que esta estratégia de alimentação não seria a mais recomendável tendo em vista os altos custos da ração frente ao limitado retorno econômico da atividade (piscicultura). Nestas circunstâncias, os agricultores testaram uma diversidade significativa de estratégias e tipos de alimentos. Entre as situações extremas (uso exclusivo de oferta natural açude e alimentação exclusiva com ração) identificou-se um conjunto de situações intermediárias em que se combinaram diferentes tipos de fontes alimentares (oferta natural do açude, pastagem, subprodutos de cultivos agrícolas e criações e ração), variando as espécies utilizadas e composição da alimentação dada aos peixes ao longo do ano segundo a disponibilidade de determinados tipos de subprodutos.

Ao analisar as mudanças tecnológicas em relação aos componentes estrutura da taipa e alimentação ressaltamos a trajetória divergente (manifesta pela grande diversidade de formatos tecnológicos experimentados e em uso por ocasião do levantamento de dados). Ao mesmo tempo, observamos que os componentes tecnológicos analisados (referentes a estrutura das taipas e alimentação) eram considerados críticos para viabilização da atividade e que os agricultores não visualizaram viabilidade nas referências técnico-cientificas (oriundas do sistema formal). Nestes casos observamos uma ativação do sistema informal para geração de alternativas viáveis às condições dos agricultores, que resultou na geração de soluções originais ou "híbridas", observando-se grande diversidade de formatos tecnológicos mobilizados, sem observar-se mudanças tecnológicas com significativa convergência de formato experimentado.

\subsubsection{Mudanças tecnológicas convergentes}

Para exemplificar processos de mudanças tecnológicas convergentes vamos abordar as trajetórias tecnológicas dos agricultores no componente formato e profundidade dos reservatórios de água e no componente diferenciação de fases na criação.

Com relação ao formato e profundidade dos reservatórios de água destinados à piscicultura, cabe contextualizar que agricultores com mais tempo na atividade relatam que utilizavam os reservatórios de água que já existiam na unidade produtiva (açudes) e que estes, via de regra, possuíam forma e profundidade irregular, seguindo o terreno observando-se, em alguns casos, que a profundidade de um

\footnotetext{
13 Convém recordar que, enquanto no modelo de integração da piscicultura preconizava-se uma alimentação com base no aproveitamento dos subprodutos de outras atividades componentes do sistema de produção (visando a máxima integração de atividades na unidade produtiva), no caso do modelo de especialização produtiva preconizava-se a utilização de ração (de origem agroindustrial) desenvolvida especificamente para cada espécie e cada fase de desenvolvimento do animal.
} 
açude poderia variar de um até oito metros. Pela observação da trajetória de cada agricultor (Figura 3) se constata que a quase totalidade dos agricultores realizou uma mudança convergente ao formato de "tanques padronizados". Estes constituem reservatórios de água destinados especificamente para piscicultura, com forma retangular e profundidade padrão (entre 1,5 e 1,2 metros).

Figura 3 - Trajetória tecnológica de cada agricultor relacionada a forma e profundidade dos reservatórios de água

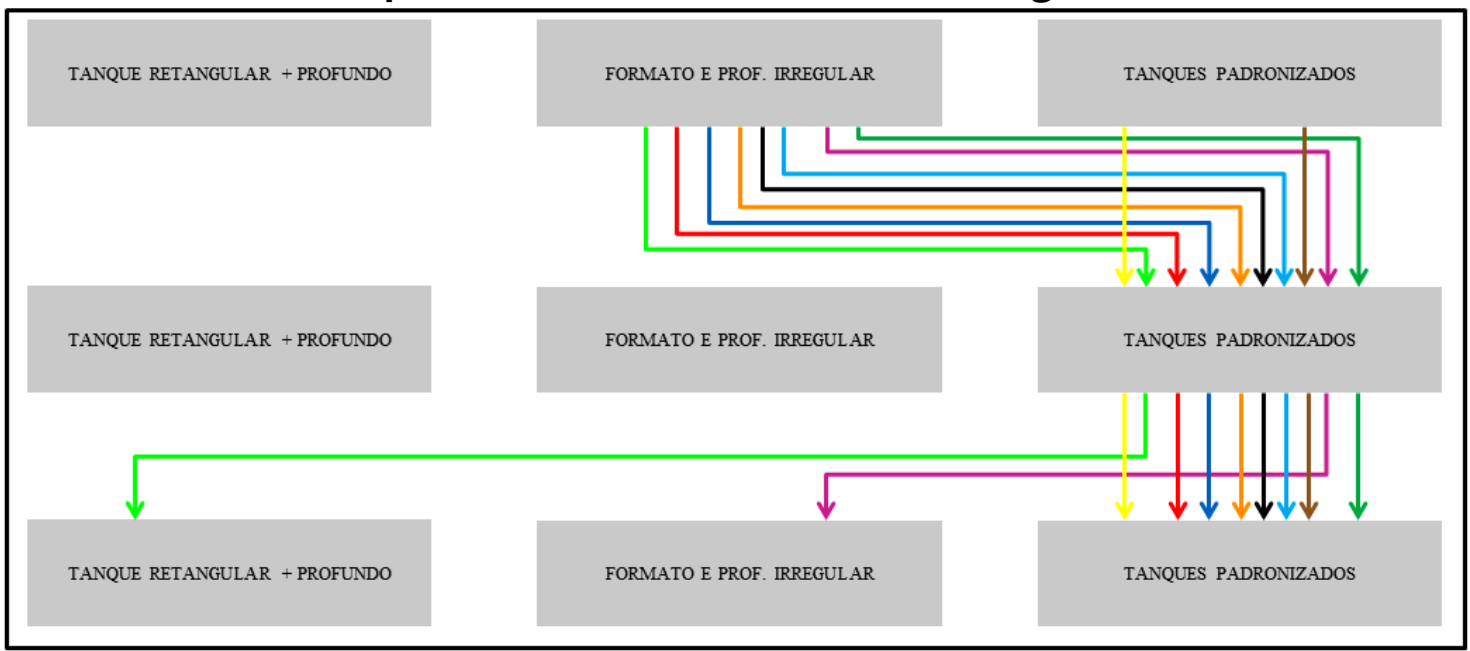

A explicação da convergência na mudança tecnológica observada quanto ao formato dos reservatórios de água remete à atuação da assistência técnica e também aos condicionantes para acesso à políticas públicas. Neste sentido, cabe ressaltar a diferença entre a orientação inicial (de aproveitamento dos recursos existentes nas unidades produtivas) e a orientação posterior (de construção de reservatórios em conformidade com recomendações técnicas específicas para piscicultura). Neste sentido, a política de fomento da SMDR - ao subsidiar a construção dos reservatórios de água - requeria apresentação de projeto técnico em conformidade com normativas de excelência técnica definidas por pesquisadores. Pode-se inferir, então, que a convergência da mudança tecnológica em favor do formato dos reservatórios de água está relacionada com a ação do Estado que, através de políticas públicas direcionadas ao setor, incentivou e fomentou a construção de reservatórios de água sob formato padronizado. Entretanto, é possível questionar se os agricultores reconheceram alguma superioridade de performance no formato padronizado pois identificam-se dois casos em que novos reservatórios de água - construídos posteriormente com recursos próprios - não seguiram o formato preconizado pelo sistema formal. Os agricultores justificaram sua escolha se referindo a disposição de aproveitar melhor a área disponível e facilitar o manejo alimentar. De acordo com o agricultor entrevistado:

Eu fui vendo como era o melhor formato de açude de lidar e fui fazendo conforme o terreno ajudava e como eu achava melhor. Pra criar peixe o açude muito pequeno não funciona. Tem que ser açude meio grande. Porque se for pequeno falta oxigênio e tem que botar muita comida, então sai muito caro. Pra gente que não é muito na tecnologia. (Produtor 9, grifo nosso) 
Na observação da trajetória relativa à diferenciação por fases de criação observa-se que, com exceção de um agricultor, todos os outros realizavam, inicialmente, todas as fases da produção em um mesmo açude. Nesse formato os peixes eram colocados em um açude grande e irregular quando alevinos e permaneciam no mesmo ambiente até o momento da despesca. Posteriormente os agricultores fizeram mudanças observando-se relativa convergência na experimentação do formato de criação de ambiente especifico para alevinos e para depuração. Na época de levantamento de dados, cinco formatos alternativos relativos a este componente tecnológico estavam em uso. ${ }^{14}$ A Figura 04 ilustra a trajetória tecnológica de cada agricultor nesse aspecto.

\section{Figura 4 - Trajetória tecnológica de cada agricultor relacionada às fases de criação}

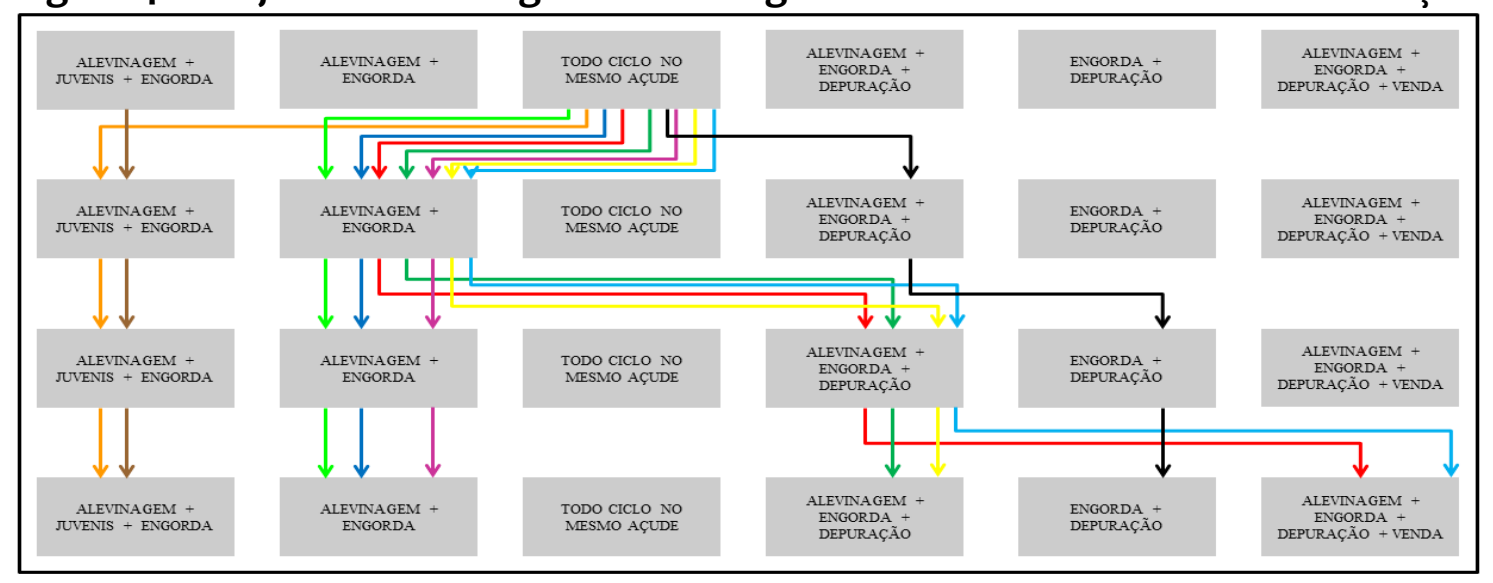

Buscando caracterizar a trajetória tecnológica, identificamos uma tendência à convergência em torno à diferenciação da fase de alevinagem, que passou a ser desenvolvida em viveiro específico ( 9 dos 10 casos estudados fizeram essa distinção), distinto do da fase de engorda. Enquanto para alguns (3 casos) o formato de diferenciação de fase de alevinagem e engorda mostrou-se adequado, outros que haviam experimentado este formato resolveram realizar novas mudanças. Posteriormente observa-se relativa convergência em torno ao reconhecimento da necessidade de diferenciar a fase de depuração. Ao investigar as razões para convergências na trajetória dos formatos tecnológicos relativos a diferenciação das fases de criação, observamos que as falas dos entrevistados remetem, sobretudo, à recomendações recebidas da assistência técnica. A construção de viveiros específicos para alevinagem e para fase de depuração, por exemplo, tem relação com a busca de maior taxa de sobrevivência dos alevinos e com a tentativa de melhoria da qualidade do peixe para a venda, pois - de acordo com relatos das entrevistas - os consumidores (da feira) reclamavam do "gosto de barro" (off flavor) no peixe. Para reduzir o "gosto de barro" a recomendação da assistência técnica foi a de utilização de um tanque específico de depuração. A realização da depuração do peixe passou a constituir, então, um aspecto condicionante da participação na Feira do Peixe Vivo, conforme orientação e exigência da Associação.

\footnotetext{
${ }^{14}$ A diversidade de formatos em uso (5) pode estar relacionada, também, à opções estratégicas dos agricultores em termos de destinação da produção ou de especialização em certas fases da criação, pois agricultores que não comercializam na feira não se preocupam em criar tanques de depuração, por exemplo.
} 
Entendemos que nos dois casos examinados nesta seção relativos a convergência na mudança tecnológica observa-se uma aproximação às referências definidas no âmbito do sistema formal e à utilização de mecanismos de incentivos ou "coercitivos" para que estas fossem implementadas. No caso da forma dos tanques, o apoio da SMDR foi condicionado à adoção do modelo preconizado e no caso das fases de criação identificamos um protagonismo da associação de piscicultores na definição destas mediante estabelecimento de condições para comercialização de peixe na feira.

\section{Considerações sobre a agência dos agricultores na interface do sistema formal e informal de conhecimento e inovação.}

O caso em estudo tratou a piscicultura como uma inovação introduzida por atores do sistema formal no contexto da agricultura de Santa Maria com vistas ao desenvolvimento rural. A introdução da piscicultura pode ser tratada como uma mudança tecnológica complexa, que foi apresentada ora como uma tecnologia com alto grau de flexibilidade (uma vez que previa adaptação de componentes do sistema de criação segundo as condições dos agricultores), ora como um "pacote tecnológico" cujos componentes estavam pré-definidos. Passadas quase três décadas da introdução da piscicultura, o levantamento de dados realizado junto aos agricultores indica que, no limite, se considera que cada agricultor utiliza um sistema de criação particular uma vez que não se observa homogeneidade quanto aos componentes materiais, técnicas e relacionamentos estabelecidos para produção e comercialização. Tal observação leva a dialogar com Glover et al. (2019) quanto às razões pelas quais se verifica tão elevada diversidade de sistemas de criação.

Pela abordagem teórica privilegiada no presente estudo, a diversidade de sistemas de criação seria esperada tendo em vista a capacidade de agência do agricultor, que incide sobre cada componente da proposta (materiais, técnicas e relacionamentos estabelecidos). Para Glover et al (2019) os estudos sobre a mudança tecnológica entre pequenos agricultores tem apontado que a disseminação de um mesmo artefato tecnológico entre diferentes atores em contextos diversos pode resultar em uma grande diversidade de configurações tecnológicas "enraizadas" às condições locais. Tais dinâmicas são compreendidas quando se considera que as práticas produtivas na agricultura familiar requerem estabelecimento de sinergias com condições agroecológicas, da unidade produtiva e do contexto social. Tais requisitos tornariam a adaptação dos formatos tecnológicos uma estratégia muito comum na agricultura familiar e se revela, no caso, no significativo número de mudanças tecnológicas realizadas por cada agricultor, para cada um dos componentes analisados. Nestas circunstâncias, considerando esta tendência à reconfiguração tecnológica com orientação adaptativa à singularidade das condições e projetos, torna-se um desafio explicar mudanças tecnológicas com convergência quanto ao formato tecnológico experimentado.

Uma das hipóteses plausíveis para explicação das convergências nas trajetórias tecnológicas remeteria à importância da aprendizagem local, da troca de conhecimentos e experiências entre agricultores que desenvolvem uma mesma atividade. Embora esta hipótese contribua para explicar convergências observadas em algumas práticas produtivas e de comercialização (não abordadas no presente 
artigo), observamos que os casos mais significativos de convergência remetem à atuação da liderança do sistema de inovação. Tal constatação leva a conferir maior atenção à atuação da liderança dos sistemas de inovação no condicionamento dos formatos tecnológicos utilizados pelos agricultores.

No caso estudado, observa-se que a atuação da liderança do sistema de inovação no condicionamento do formato tecnológico utilizado pelos agricultores se diferenciou ao longo do tempo. Ao se recompor o histórico de formação dos sistemas de inovação no caso estudado, tomando por base a tipologia proposta por Engel (1997), tendemos a considerar que a configuração inicial do sistema de inovação estaria mais próxima ao tipo policy driven - ou seja, de um sistema que persegue objetivos políticos. Tal tipo remete ao protagonismo da EMATER/RS na busca do objetivo político de diversificação produtiva no âmbito da "pequena produção" como estratégia de desenvolvimento rural. Uma vez que se perseguia a integração da piscicultura nos sistemas de produção, tornava-se necessária a adaptação dos componentes tecnológicos à realidade de cada unidade produtiva, reconhecendo-se - consequentemente- a desejabilidade da participação do agricultor neste processo. Tal configuração corresponde a um processo do tipo innovating with farmers (SMITH; BARGDON, 2015). Entendemos que, sob estas circunstancias, cabe a liderança do sistema fomentar a diferenciação mais do que a padronização de formatos tecnológicos. ${ }^{15}$

A medida em que os agricultores se organizaram para comercializar a produção e assumiram uma participação mais ativa no âmbito da liderança do sistema de inovação, podemos caracterizar uma aproximação de sistema de inovação do tipo farmer driven (ENGEL, 1997). Neste contexto destaca-se o esforço pela definição de um projeto coletivo: um entendimento comum sobre os desafios a serem enfrentados para consolidar a comercialização dos peixes. ${ }^{16}$ Nestes marcos os atores consideraram que a consolidação da feira dependeria da qualificação da criação de peixes, com vistas a gerar o produto almejado pelo consumidor em termos de espécie, peso e sabor e que a qualificação da piscicultura exigiria uma "profissionalização" dos piscicultores. A "profissionalização", por sua vez, estaria caracterizada pela condução da piscicultura como atividade especializada, em estrita observância à recomendações técnicas pré-definidas - do que deriva-se a necessidade de definir e promover a utilização de um "pacote tecnológico" de referência. Assim, a profissionalização da piscicultura implica na aproximação de um processo do tipo innovating for farmers (SMITH; BARGDON, 2015) ${ }^{17}$ e também na ativação de mecanismos diversos com vistas ao incentivo e controle dos formatos tecnológicos em uso. Nestas circunstâncias as lideranças passaram a ser mais ativas na disseminação de referências (através de palestras, cursos e dias de campo) e no

15 Cotrim (2002, p.3) menciona que experiencias com piscicultura conduzidas na região norte do RS durante a década de 1980 possibilitaram o desenvolvimento de "um método de criação rustico" que veio a servir de referência para a materialização o projeto de piscicultura a baixo custo, integrada as demais atividades da unidade produtiva. Para contextualizar esse processo na trajetória da piscicultura brasileira ver Silva (2005).

${ }^{16}$ Cabe observar que, no caso, os atores parecem ter adotado uma leitura amplamente difundida sobre "desafios para desenvolvimento da piscicultura", a qual pode ser reconhecida nos trabalhos de Cotrim (2002) e Balisserotto (2009), por exemplo.

17 Reconhecemos que, conforme literatura, não seria esperada a associação de uma configuração farmer led com uma orientação innovating for farmers. Compreendemos que as situações reais tendem a ser mais complexas que os tipos ideais e que, no caso, a orientação pode derivar da natureza do projeto coletivo. 
desenvolvimento de mecanismos de controle (estabelecimento de condições para acesso a recursos públicos, condições para a comercialização do pescado, entre outras).

Embora reconheçamos o esforço da liderança dos sistemas de inovação em prol da profissionalização da piscicultura (o que propiciaria a padronização dos formatos tecnológicos com decorrente redução da diferenciação associada a agência do agricultor), a diversidade das trajetórias e formatos tecnológicos em uso evidencia a irredutibilidade da condição do agricultor a adotante de tecnologias oriundas do sistema formal. Para explicar a especificidade da dinâmica observada podemos nos referir a eventual divergência de projeto das lideranças em relação aos projetos dos agricultores, a qual tem implicação sobre formatos tecnológicos considerados desejáveis. Neste sentido, com base em depoimentos recolhidos em entrevistas, pressupomos que a adoção de formatos oriundos no sistema formal requereria do agricultor a realização de investimentos de recursos escassos e, portanto, a priorização desta atividade, seguindo uma "lógica da priorização da piscicultura" em contraposição à "lógica adaptativa" (privilegiada pelos agricultores, sobretudo por aqueles com recursos escassos). Sob a lógica de priorização a gestão é realizada com vistas a criação das condições ideais para o desenvolvimento da atividade fim (piscicultura), enquanto sob a lógica adaptativa, prioriza-se a viabilização do sistema de produção e os projetos das famílias (e não de uma atividade específica). No caso, enquanto alguns (poucos) manifestam certa identificação profissional com a atividade, para a maioria ela se constituiu uma atividade produtiva complementar. Então, esses agricultores buscam "encaixar" a atividade (piscicultura) em suas estratégias sócio-produtivas diversas. A interpretação da agência do agricultor considerando-se a maior disposição à adoção de uma lógica adaptativa permite um novo olhar sobre os dados observados. Neste sentido, tendemos a supor que os agricultores detinham diferentes materiais (tanto em relação as condições agroecológicas, recursos para investimento e as espécies distribuídas pelo Programa de Fomento - que variaram cada ano), conhecimento diferenciado sobre técnicas e também inserções (posições) diferenciadas na cadeia produtiva. Estas diferenças propiciaram a realização de combinações de materiais-técnicas-relações, resultando na diferenciação dos sistemas de criação. Se a lógica adaptativa for tomada como pressuposto para interpretar a agência do agricultor na interface dos sistemas formal e informal de conhecimento explica-se, também, a diversidade de soluções "ad hoc" encontradas para enfrentamento de problemas técnicos surgidos o desenvolvimento da atividade (consideramos o caso da diversidade de formato das taipas como ilustrativo neste aspecto). O caso do formato tecnológico adotado em relação a questão da alimentação também pode ser considerado bastante emblemático. A adoção de uma lógica adaptativa leva a considerar que o alimento fornecido aos peixes pode variar estacionalmente e conforme a disponibilidade e oportunidade específica em cada ano, o que confere fluidez às práticas produtivas utilizadas.

Do exposto tendemos a interpretar que a dinâmica observada no caso em estudo aponta para a pertinência das noções de sistema de inovação e agencia do agricultor na interpretação das mudanças tecnológicas ao mesmo tempo em que sugere atenção à condições particulares dos processos de intervenção para o desenvolvimento, que podem favorecer ou dificultar a maior agencia do agricultor. Generalizando-se podemos considerar que a coordenação do sistema de inovação 
age como força centrípeta (de convergência) num ambiente propenso à dominância de forças centrífugas (fruto da agencia do agricultor, de diferenciação de formatos tecnológicos com vistas a adaptação dos sistemas de criação às condições particulares de cada agricultor).

\section{Considerações finais}

Um esforço como o realizado nesta pesquisa leva a reconhecer que nossa visão usual sobre inovação pode estar enviesada na medida em que compartilhamos globalmente um imaginário de desenvolvimento que remete o "foco" das investigações à "ciência" e à promoção da difusão/adoção de seus produtos. Num contexto em que se renovam os paradigmas sobre o desenvolvimento e a agricultura, e que as agendas políticas conferem maior destaque à questões relativas à sustentabilidade, a presente pesquisa evidencia a necessidade de revisar a forma de perceber os processos de inovação, bem como a necessidade de utilização de uma abordagem atenta à diversidade e complexidade dos mesmos.

Com base em estudo de caso sobre introdução e desenvolvimento da piscicultura em Santa Maria, RS, refletimos a respeito da agência do agricultor na interface dos sistemas formal e informal de conhecimento e inovação. De modo geral, a partir do estudo convergimos com Glover et al. (2019) no reconhecimento da contribuição das abordagens construtivistas que conferem atenção especial à agencia de indivíduos e grupos e às formas como a tecnologia é reconstruída e reconfigurada a medida que se move de uma situação (e comunidade de práticas à outra). Também convergimos com estes autores quanto a relevância de reconceptualizar os processos de difusão-adoção de inovações, reconhecendo a necessidade de conferir atenção aos processos de proposição, aos encontros de interface, às disposições que podem estar na base da diferenciação das respostas à uma mudança tecnológica "deliberadamente estimulada e orquestrada".

Entretanto, complementarmente à abordagem de Glover et al (2019), a presente pesquisa apontou para a importância da consideração dos sistemas de inovação, que atuam no sentido de coordenar e, de certo modo, convergir a agencia dos diferentes atores que participam de um processo de inovação com vistas a assegurar determinado performance para o coletivo.

Embora reconhecendo os limites de generalização do caso - tendo em vista tratar-se de mudança tecnológica complexa em uma atividade produtiva considerada "complementar" pelos agricultores - entendemos que são cabíveis reflexões em torno ao papel dos "promotores da mudança". Neste sentido, as indicações recolhidas com a realização da pesquisa apontam para o reconhecimento de que mudanças tecnológicas complexas - como aquelas orientadas a promover a sustentabilidade/ enraizamento local dos sistemas produtivos - vão implicar em reconfigurações das propostas tecnológicas a partir da agencia dos agricultores. 0 reconhecimento desta dinâmica pode implicar na conveniência de estudar este processo com vistas ao reconhecimento dos pontos críticos identificados pelos agricultores nas propostas tecnológicas e tendências quanto as suas preferências (GLOVER et al., 2019) e também para orientar os processos de coordenação, evitando a formulação e adoção de normas potencialmente excludentes. 


\section{REFERÊNCIAS}

BALDISSEROTTO, B. Piscicultura continental no Rio Grande do Sul: situação atual, problemas e perspectivas para o futuro. Ciência Rural, Santa Maria, v.39, n.1, p.291299, jan./fev. 2009.

BENOUNICHE, M.; ZWARTEVEEN, M.; KUPER, M. Bricolage as innovation: opening the black box of drip irrigation systems. Irrigation and Drainage, 2014.

BONNY, I.; GIULIANI, F. Configurations et trajectoires de l'innovation institutionnelle. Une introduction. Socio-logos, n.7, 2012.

CALGARO NETO, S. O mapeamento de redes interpessoais como ferramenta para o desenvolvimento de organizações sociais. 2008. Trabalho de Conclusão de Curso (Engenharia Florestal) - Universidade Federal de Santa Maria. Santa Maria - RS, 2008.

CALGARO NETO, S.; DIESEL, V. Redes sociais e constituição de referentes técnicos em cooperativa de piscicultores em Santa Maria, RS. In: Congresso da Sober, 47, 2009, Porto Alegre, RS. Anais... Porto Alegre, RS: [s.n], 2009.

CANCELIER, J.W.; MOURAD, L.A. de F. A.P.; CASSOL, K.P. Os múltiplos usos do espaço rural no município de Santa Maria - RS: Tendências atuais da agricultura familiar. Geografia em Questão, v.10, n.01, p. 135-154, 2017.

CARDOSO, E. S.; ROCHA, H. M. O.; FURLAN, M. C. A piscicultura no município de Santa Maria, RS. Ciência e Natura, Santa Maria, v. 31, n. 1, p. 131-140, 2009

CHAMBERS, R. Desenvolvimento Rural: Fazer dos últimos os primeiros. Luanda: ADRA, 1995.

CHAMBERS, R. Can we know better? Reflections for development. Rugby, UK: Practical Action Publishing, 2017. 194p.

COTRIM, D.S. Piscicultura: manual prático, Porto Alegre: EMATER-RS, 1995. 37 p.

COTRIM, D.S. Comércio local de peixe cultivado na região metropolitana de Porto Alegre. 2002. Monografia (Curso de Pós-Graduação em Desenvolvimento, Agricultura e Sociedade) - Universidade Federal Rural do Rio de Janeiro, Rio de Janeiro, 2002.

DEVERRE, C.; LAMINE, C. Les systèmes agralimentaires alternatifs. Une revue de travaux anglophones em sciences sociales. Économie rurale, n.317, p.57-73, mai/juin 2010.

DOCKÈS, A-C.; TISENKOPFS, T.; BOCK, B. Collaborative Working Group Agricultural Knowledge and Innovation Systems. WP1: Reflection Paper on AKIS. Sub- 
Deliverable of the AKIS CWG-WP1. European Commission: Brussels, Belgium, April 2011.

ENGEL, P. G.H. The social organization of innovation: A foccus on stakeholder interaction. Amsterdam: Royal Tropical Institute, 1997. 236p.

ESCOBAR, A. Encountering Development: The Making and Unmaking of the Third World. Princenton, N.J: Princenton University Press, 1995.

FAURE, G. et al. How to strenghten Innovation Support Services in Agriculture with Regard to Multi-Stakeholder Approaches. Journal of Innovation Economics \& Management, n.28, p.145-169, 2019/1.

FRESSOLI, M.; AROUND, E. Technology for Autonomy and Resistance: The Appropriate Technology Movement in South America. Bringhton: STEPS Centre, 2015. STEPS Working Paper 87.

GFRAS. Building Knowledge Systems in Agriculture. Lindau: GFRAS, 2012. Position Paper.

GLOVER, D.; SUMBERG, J.; TON, G.; ANDERSSON, J.; BADSTUE, L. Rethinking technological change in smallholder agriculture. Outlook on Agriculture, v.48, n.3, p.169-180, 2019.

HIRVONEN, M. Tourist guide to systems studies of rural innovation. LINK/UNU/FAO, 2009. Link Policy Resources on Rural Innovation Series, n.1.

INSTITUTO BRASILEIRO DE GEOGRAFIA E ESTATÍSTICA. Censo Agropecuário 2006. Rio de Janeiro: IBGE, 2006.

INSTITUTO BRASILEIRO DE GEOGRAFIA E ESTATÍSTICA. Censo Agropecuário 2017. Rio de Janeiro: IBGE, 2007.

LIMA, A. F.; SILVA, A. P.; GUEDES, C.; BERGAMIN, G. T.; PEDROZA FILHO, M. X.; MACIEL, P. O. Construção de viveiros: piscicultura familiar. Projeto Divinópolis: Inovação tecnológica na piscicultura familiar. Embrapa Pesca e Aquicultura. Divinópolis - TO, 2013 a.

LIMA, A. F.; SILVA, A. P.; RODRIGES, A. P. O.; BERGAMIN, G. T.; PEDROZA FILHO, M. X.; MACIEL, P. O. Alevinagem: piscicultura familiar. Projeto Divinópolis: Inovação tecnológica na piscicultura familiar. Embrapa Pesca e Aquicultura. Divinópolis - TO, 2013b.

LIMA, A. F.; SILVA, A. P.; RODRIGES, A. P. O.; BERGAMIN, G. T.; PEDROZA FILHO, M. X.; MACIEL, P. O. Preparação de viveiros: piscicultura familiar. Projeto Divinópolis: Inovação tecnológica na piscicultura familiar. Embrapa Pesca e Aquicultura.

Divinópolis - TO, 2013C. 
LIMA, A. F.; SILVA, A. P.; RODRIGES, A. P. O.; BERGAMIN, G. T.;TORATI, L. S.; PEDROZA FILHO, M. X.; MACIEL, P. O. Qualidade da água: piscicultura familiar. Projeto Divinópolis: Inovação tecnológica na piscicultura familiar. Embrapa Pesca e Aquicultura. Divinópolis - TO, 2013d.

LIMA, A. F.; SILVA, A. P.; RODRIGES, A. P. O.; BERGAMIN, G. T.;TORATI, L. S.; PEDROZA FILHO, M. X.; MACIEL, P. O. Manejo Alimentar: piscicultura familiar. Projeto Divinópolis: Inovação tecnológica na piscicultura familiar. Embrapa Pesca e Aquicultura. Divinópolis - TO, $2013 e$.

LONG, N. Sociologia del desarrollo: una perspectiva centrada em El actor. México: Centro de investigaciones y estudios superiores em antropologia social: El Colegio de San Luis, 2007, 504p.

ROGERS, E.M. Elementos de cambio social: Difusión de Innovaciones. Bogota: Ediciones Tercer Mundo/ Facultad de Sociologia, 1966

ROGERS, E.M. Diffusion of Innovations. 5 ed. New York: Free Press, 2003 SMITH, C.; BARGDON, S.H. Small-scale farmer innovation systems: A review of current literature. Geneva: Quaker United Nations Office, 2015.

SILVA, N.J.R. da Dinâmicas de desenvolvimento da piscicultura e políticas públicas no Vale do Ribeira/ SP e Alto Vale do Itajaí/ SC - Brasil. 2005. Tese (Curso de PósGraduação em Aquicultura) - Universidade Estadual Paulista/ Ecole National Superieur Agronomique de Rennes. Jaboticabal , 2005.

TOURAND, J-M.; TEMPLE, L.; FAURE, G.; TRIOMPHE, B. Innovation Systems and knowledge communities in the agriculture and agriffod sector: A literature review. Journal of Innovation Economics \& Management, n.1, p.117-142, 2015.

Iolanda Araujo Ferreira dos Santos. Engenheira de Pesca (Universidade Federal Rural de Pernambuco), Mestra e Doutora em Extensão Rural (Universidade Federal de Santa Maria).iolanda_uast@yahoo.com.br

Vivien Diesel. Doutora em Desenvolvimento Socioambiental (UFPA) com PósDoutorado em Antropologia Social (Universidad de Sevilla - Espanha), Professora Titular da UFSM, com atuação no Programa de Pós-graduação em Extensão Rural (na época de submissão do artigo).viviendiesel@yahoo.com.br 
Como citar: DOS SANTOS, Iolanda Araujo Ferreira; DIESEL, Vivien. Agência dos agricultores na interface dos sistemas formal e informal de conhecimento e inovação. Redes (St. Cruz Sul, Online), Santa Cruz do Sul, v. 25, n. 1, jan. 2020. ISSN 1982-6745.

DOI: https://doi.org/10.17058/redes.v25i1.14683.

\section{CONTRIBUIÇÃO DE CADA AUTORA}

Fundamentação teórico-conceitual e problematização: Vivien Diesel Pesquisa de dados e análise estatística: Iolanda Araujo Ferreira dos Santos Elaboração de figuras e tabelas: Iolanda Araujo Ferreira dos Santos Fotos: não se aplica Elaboração e redação do texto: Iolanda Araujo Ferreira dos Santos e Vivien Diesel Seleção das referências bibliográficas: Vivien Diesel e Iolanda Araujo Ferreira dos Santos 